\title{
Impact of COVID-19 lockdown in patients with implantable cardioverter and cardiac resynchronization therapy defibrillators: insights from daily remote monitoring transmissions
}

\author{
Giosuè Mascioli ${ }^{1} \cdot$ Elena Lucca $^{1} \cdot$ Paola Napoli $^{2} \cdot$ Daniele Giacopelli ${ }^{2,3}$
}

Received: 18 January 2021 / Accepted: 19 March 2021 / Published online: 29 March 2021

(c) Springer Japan KK, part of Springer Nature 2021

\begin{abstract}
In Italy, a strict lockdown was imposed from 8 March 2020 to stop the spread of the coronavirus disease 2019 (COVID-19). We explored the effect of this lockdown on data transmitted by remote monitoring (RM) of implantable cardioverter and cardiac resynchronization therapy defibrillators (ICDs/CRT-Ds). RM daily transmissions from ICDs and CRT-Ds were analyzed and compared in two consecutive 1 month frames pre and post-lockdown: period I (7 February-7 March 2020) and period II (8 March-7 April 2020). The study cohort included 180 patients (81.1\% male, 63.3\% ICDs and 36.7\% CRT-Ds) with a median age of 70 (interquartile range 62-78) years. The median value of physical activity provided by accelerometric sensors showed a significant reduction between period I and II [13.1\% (8.2-18.1\%) versus 9.4\% (6.3-13.8\%), $p<0.001]$. Eighty nine $\%$ of patients decreased their activity, for $43.3 \%$ the relative reduction was $\geq 25 \%$. The mean heart rate decreased significantly [69.2 (63.8-75.6) bpm vs $67.9(62.7-75.3) \mathrm{bpm}, p<0.001]$, but with greater reduction $(\approx 3$ beats/minute) in patients aged $<70$ years. Resting heart rate and thoracic impedance showed minor variations. No differences were observed in device pacing $\%$ and arrhythmias. In cardiac patients, the lockdown imposed to contain COVID-19 outbreak significantly reduced the amount of physical activity and the mean heart rate. These side effects of in-home confinement quarantine should be taken in consideration for frail patients.
\end{abstract}

Keywords Remote monitoring · Implantable cardioverter defibrillator · Cardiac resynchronization therapy · COVID-19 . Lockdown

\section{Introduction}

In January 2020, severe acute respiratory syndrome coronavirus 2 (SARS-CoV-2) was identified as the infectious agent responsible for the COVID-19 disease [1]. The first cases of COVID-19 infection were reported in the city of Wuhan (Hubei province, China) in December 2019 and rapidly grew

Giosuè Mascioli

giosue.mascioli@gavazzeni.it

Daniele Giacopelli

daniele.giacopelli@biotronik.com

1 Department of Cardiology, Humanitas Gavazzeni Hospital, Via Mauro Gavazzeni, 21, 24125 Bergamo, Italy

2 Clinical Research Unit, Biotronik Italia, Vimodrone, Milano, Italy

3 Department of Cardiac, Thoracic, Vascular Sciences and Public Health, University of Padova, Padua, Italy in several countries worldwide [2]. On 30 January 2020, the World Health Organization (WHO) declared the outbreak of SARS-CoV-2 a "Public Health Emergency of International Concern" [3] and a pandemic situation on 11 March 2020 [4].

Due to the lack of specific treatment or vaccines for COVID-19, "lockdown" measures, including staying at home, movement and travel restrictions, physical distancing, school and workplace closures, were adopted in various countries to limit human-to-human transmission of the coronavirus [5]. Italy was one of the most-affected countries in Europe [6] and Bergamo, in the Lombardy region, among northern Italian cities worst-hit by the pandemic [7-9]. As of March 8, 2020, the Italian government imposed a lockdown of the Lombardy region and of the whole country on March 11,2020 [10].

Despite the effectiveness of these protective measures in containing the virus spread [11, 12], careful attention should be paid to their impact on health condition of patients who 
are compelled to prolonged in-home confinement and isolation. Using remote monitoring (RM) technologies, heart failure patients implanted with cardiac implantable electronic devices can transmit automatically a broad spectrum of variables associated with the clinical status of the patient that can be used to improve healthcare delivery. We performed a retrospective analysis of RM data transmitted from patients with implantable cardioverter and cardiac resynchronization therapy defibrillators (ICDs and CRT-Ds) to investigate the effect of COVID-19 pandemic lockdown on the RM variables.

\section{Materials and methods}

\section{Study objective}

The aim of this exploratory data analysis was to investigate the impact of COVID-19 lockdown on the variables transmitted by ICDs and CRTDs in the cohort of patients followed using a daily RM technology at the Humanitas Gavazzeni hospital in Bergamo, Lombardy, Italy. For this purpose, we compared RM data in two consecutive time windows of 1 month indexed at the date of COVID-19 lockdown. This analysis was performed in accordance with the ethical standards of the Institutional Research Committee and with the 1964 Helsinki declaration and its later amendments. Before RM registration, all patients provided written informed consent including the use of RM data without any detail that might disclose the identity of subjects for clinical research purposes. The data that support the findings of this study are available from the corresponding author upon reasonable request.

\section{Home monitoring technology}

The Home Monitoring ${ }^{\circledR}$ technology (BIOTRONIK SE \& Co. KG, Berlin, Germany) is a RM system for cardiac implantable electronic devices characterized by automatic and daily transmissions of a broad spectrum of technical and clinical variables. These data that are commonly stored in the device memory are also transmitted via wireless to a secure data server (i.e. BIOTRONIK-HM Service Center) using a portable patient unit. Collected data can be accessed and reviewed by physicians through a protected website similarly to in-person device follow-ups.

\section{Data analysis and statistics}

The primary analysis was the assessment of variations of RM parameters, as a result of prolonged home stay and lifestyle changes, after the implementation of the COVID-19 lockdown on 8 March 2020. Two consecutive time windows of 1 month were considered:

- Period I: 7 February-7 March 2020

- Period II: 8 March-7 April 2020

We analyzed the following variables: RM daily transmission rate defined as the \% of days covered by successful RM transmission, physical activity provided by an accelerometric sensor, thoracic impedance (TI), mean heart rate (HR), resting heart rate (rHR), frequency of premature ventricular contractions (PVCs), atrial and right ventricular pacing percentage, CRT pacing \%, HR variability, atrial fibrillation (AF) episodes, number of anti-tachycardia pacing (ATP) and high-energy shock delivered due to ventricular arrhythmias. Median values were calculated and compared between period I and period II with the Wilcoxon matched-pairs test or the two-sample proportion test as appropriate. Continuous variables were reported as median [interquartile range (IQR)] and binary or categorical variables as \%. An additional analysis according to patient age was performed using the median age to define two subgroups of patients. Finally, a comparison of baseline characteristics between subgroups with different variation of physical activity $(\geq 25$ and $<25 \%)$ was performed. Between-group differences were tested with the Mann-Whitney $U$ test for continuous variables and with Pearson $\chi^{2}$ test for binary variables. Statistical calculation was performed using the STATA version 11 software (StataCorp LP, College Station, TX, USA).

\section{Results}

\section{Study cohort}

Our study population included a total of 180 patients with at least one RM transmission both in Period I and II. Table 1 shows baseline clinical characteristics of the entire study cohort. Most patients were male $(81.1 \%)$ with a median age of 70 (IQR $62-78$ ) years (55\% of the patients were aged $\geq 70$ years). Patients with single chamber, dual chamber ICDs and CRT-Ds were $36.1 \%, 27.2 \%$ and $36.7 \%$, respectively. The majority of patients was implanted for primary prevention (78.3\%) and had ischaemic (47.2\%) or dilated (23.3\%) cardiomyopathy.

\section{Impact on home monitoring variables}

The results of the analyzed RM parameters on the overall population are reported in Table 2 . The RM daily transmission rate was generally very high with a slight increase during COVID-19 lockdown [97\% (IQR 93-100\%) vs 97\% (IQR $97-100 \%), p=0.041]$. The comparison of median 
Table 1 Baseline population characteristics

\begin{tabular}{lc}
\hline & $\begin{array}{l}\text { Total } \\
(n=180)\end{array}$ \\
\hline Sex, male & $146(81.1)$ \\
Age (years) & $70(62-78)$ \\
ICD type & \\
Single chamber & $65(36.1)$ \\
Dual chamber & $49(27.2)$ \\
Biventricular & $66(36.7)$ \\
Indication for defibrillator & \\
Primary prevention & $141(78.3)$ \\
Secondary prevention & $37(20.5)$ \\
Other & $2(1.1)$ \\
Underlying heart disease & \\
Ischaemic cardiomyopathy & $85(47.2)$ \\
Dilated cardiomyopathy & $42(23.3)$ \\
Hypertrophic cardiomyopathy & $4(2.2)$ \\
Arrhythmogenic right ventricular dysplasia & $7(3.9)$ \\
Brugada & $14(7.8)$ \\
Valvular heart disease & $12(6.7)$ \\
Other & $12(6.7)$ \\
None & $4(2.2)$ \\
\hline
\end{tabular}

Data are shown as median (interquartile range) and $n(\%)$ for binary variables

values showed a significant reduction of physical activity [13.1\% (IQR $8.2-18.1 \%$ ) vs $9.4 \%$ (IQR 6.3-13.8\%), $p<0.001]$. The relative reduction of physical activity was of 21.6\% (IQR 35.2-10.4\%). Also, the mean HR decreased significantly [69.2 (IQR 63.8-75.6) bpm vs 67.9 (IQR 62.7-75.3) bpm, $p<0.001]$. A less remarkable, but statistically significant, reduction of rHR and increase of TI were also observed (Table 2). No differences were found for the other parameters between the two time periods.

\section{Age subgroups}

Table 3 summarizes the analysis by age subgroup (i.e. $<70$ and $\geq 70$ years) between periods I and II. Patients aged less than 70 years had more consistent reductions of physical activity $[\approx 5 \%$, a median relative decrease of $23.1 \%$ (IQR 38-11.4\%)], mean HR ( $\approx 3$ beats/minute) and rHR $(\approx 2$ beats/minute). In addition, we observed a significant increase of atrial pacing percentage $(\approx 2 \%)$ and TI $(\approx 1 \Omega)$. Young patients with at least one AF episode appeared also to increase the time spent in atrial arrhythmia [99.9\% (IQR $0.4-100 \%$ ) vs $99.9 \%$ (IQR $4.4-100 \%$ ), $p=0.048]$. In the subgroup of elderly patients, the reduction of physical activity [-19.3\% (IQR 33-9.8\%)] was significant, but less remarkable due to a lower baseline value [10.6\% (IQR 6.7-16.2\%)]. Mean HR, TI and CRT pacing percentage showed small increases, while no difference was found in rHR.

Daily temporal trends indexed at lockdown date (time zero) of physical activity, TI, mean HR and rVHR in the overall population and subgroups are depicted in Fig. 1.
Table 2 Median values of daily remote monitoring transmissions in period I (1 month pre-lockdown) and II (1 month post-lockdown) in the entire study cohort $(n=180)$

\begin{tabular}{lllr}
\hline & $\begin{array}{l}\text { Period I (1 month pre- } \\
\text { lockdown) }\end{array}$ & $\begin{array}{l}\text { Period II (1 month } \\
\text { post-lockdown) }\end{array}$ & $p$ value \\
\hline RM daily transmission rate (\%) & $97.0(93.0-100)$ & $97.0(97.0-100)$ & 0.041 \\
Physical activity (\%) & $13.1(8.2-18.1)$ & $9.4(6.3-13.8)$ & $<0.001$ \\
Thoracic impedance (Ohm) & $74.4(66.5-80)$ & $74.9(68.5-81)$ & $<0.001$ \\
Mean heart rate (bpm) & $69.2(63.8-75.6)$ & $67.9(62.7-75.3)$ & $<0.001$ \\
Resting heart rate (bpm) & $60(54.3-66.2)$ & $59.8(53.5-66.8)$ & 0.004 \\
Frequency of PVCs $(n /$ hour) & $2.2(0-45.7)$ & $1.2(0-41.2)$ & 0.298 \\
Atrial pacing percentage (\%) & $15.2(0.3-47.8)$ & $13.2(0.6-48.4)$ & 0.102 \\
Right ventricular pacing percentage (\%) & $1.3(0-92.4)$ & $1.4(0-92.8)$ & 0.853 \\
CRT pacing percentage (\%) & $98.6(95.1-99.8)$ & $98.8(96.6-100)$ & 0.183 \\
PP variability (ms) & $83.5(54.7-102.0)$ & $78.6(57-101.8)$ & 0.143 \\
Number of patients with AF episodes, $n(\%)$ & $18(14.3)$ & $19(15.1)$ & 0.859 \\
24 h AF burden ${ }^{*}(\%)$ & $100(2-100)$ & $100(4.4-100)$ & 0.126 \\
Number of patients with ATP, $n(\%)$ & $3(1.7)$ & $3(1.7)$ & 1.000 \\
Number of patients with shock $n(\%)$ & $1(0.6)$ & $3(1.7)$ & 0.315 \\
\hline
\end{tabular}

Data are shown as median (interquartile range) and $n(\%)$ for binary variables

$R M$ remote monitoring, $P V C s$ pre-ventricular contractions, $C R T$ cardiac resynchronization therapy, $A F$ atrial fibrillation, ATP anti-tachycardia pacing

${ }^{\mathrm{a}}$ Considering only patients with at least one AF episode 
Table 3 Median values of daily remote monitoring transmissions in period I (1 month pre-lockdown) and II (1 month post-lockdown) in patients aged $<70$ years $(n=81)$ and aged $\geq 70$ years $(n=99)$

\begin{tabular}{|c|c|c|c|c|c|c|}
\hline & \multicolumn{3}{|c|}{ Patients aged $<70$ years } & \multicolumn{3}{|c|}{ Patients aged $\geq 70$ years } \\
\hline & $\begin{array}{l}\text { Period I (1 month } \\
\text { pre-lockdown) }\end{array}$ & $\begin{array}{l}\text { Period II (1 month } \\
\text { post-lockdown) }\end{array}$ & $p$ value & $\begin{array}{l}\text { Period I } \\
\text { (1 month pre- } \\
\text { lockdown) }\end{array}$ & $\begin{array}{l}\text { Period II } \\
(1 \text { month post- } \\
\text { lockdown })\end{array}$ & $p$ value \\
\hline $\mathrm{RM}$ daily transmission rate $(\%)$ & $97.0(88.5-100)$ & $97.0(95.5-100)$ & 0.109 & $97.0(93.0-100)$ & $97.0(97.0-100)$ & 0.177 \\
\hline Physical activity (\%) & $16.1(10.8-21.6)$ & $11.4(8.6-15.2)$ & $<0.001$ & $10.6(6.7-16.2)$ & $8.2(4.5-11.7)$ & $<0.001$ \\
\hline Thoracic impedance (ohm) & $74.5(66.5-78.8)$ & $75.2(69.0-79.5)$ & $<0.001$ & $73.8(66.3-80.5)$ & $74.6(66.7-82.0)$ & 0.013 \\
\hline Mean heart rate (bpm) & $71.3(65.1-78.8)$ & $68.1(62.8-76.8)$ & $<0.001$ & $67.2(63.2-73.8)$ & $67.8(62.0-74.0)$ & $<0.001$ \\
\hline Resting heart rate (bpm) & $60.2(52.2-67.9)$ & $58.0(52.1-66.1)$ & $<0.001$ & $60.0(54.6-65.4)$ & $60.0(54.7-67.2)$ & 0.402 \\
\hline Frequency of PVCs ( $n /$ hour) & $0.4(0-40.5)$ & $0.1(0-31.6)$ & 0.365 & $5.7(0-68.7)$ & $1.6(0.1-68.4)$ & 0.448 \\
\hline Atrial pacing percentage $(\%)$ & $8.9(0.1-23)$ & $10.8(0.4-30.7)$ & 0.012 & $23.1(0.5-57.8)$ & $18.3(0.6-56.6)$ & 0.815 \\
\hline Right ventricular pacing percentage $(\%)$ & $0.3(0-4.6)$ & $0.3(0-4.4)$ & 0.696 & $11.1(0.2-97.2)$ & $10.5(0.3-96.4)$ & 0.946 \\
\hline CRT pacing percentage $(\%)$ & $96.0(95.1-99.8)$ & $98.7(93.6-100)$ & 0.528 & $98.6(94.7-99.9)$ & $98.9(96.7-100)$ & 0.048 \\
\hline PP variability (ms) & $93.9(69.1-114.7)$ & $89.9(71.6-112.7)$ & 0.120 & $70.1(36.5-86.7)$ & $70.9(38.1-88.9)$ & 0.673 \\
\hline Number of patients with AF episodes $n(\%)$ & $7(11.9)$ & $9(15.2)$ & 0.591 & $11(16.7)$ & $10(15.1)$ & 0.812 \\
\hline 24 h AF burden $*(\%)$ & $99.9(0.4-100)$ & $99.9(4.4-100)$ & 0.048 & $100(17.5-100)$ & $100(4.1-100)$ & 0.723 \\
\hline Number of patients with ATP $n(\%)$ & $1(1.3)$ & $1(1.3)$ & 1.000 & $2(2.1)$ & $2(2.1)$ & 1.000 \\
\hline Number of patients with shock, $n(\%)$ & $1(1.3)$ & $2(2.5)$ & 0.560 & $0(0)$ & $3(1.0)$ & 0.316 \\
\hline
\end{tabular}

Data are shown as median (interquartile range) and $n(\%)$ for binary variables

$R M$ remote monitoring, $P V C$ pre-ventricular contraction, $C R T$ cardiac resynchronization therapy, $A F$ atrial fibrillation, $A T P$ anti-tachycardia pacing

${ }^{\text {a }}$ Considering only patients with at least one AF episode

\section{Characteristics of patients with physical activity drop}

Figure 2 shows \% distribution of patients according to different levels of activity variation. Eighty nine \% of patients decreased their activity during the lockdown period. Among them, 78 patients showed a relative reduction $\geq 25 \%$. Patients with the most remarkable physical activity reduction were more likely to be men compared ( 94.9 vs $70.6 \%, p<0.001$ ) than the rest of the cohort, while no age differences were found (Table 4).

\section{Discussion}

There are few studies on the effects of COVID-19 lockdown on people isolated at home for a prolonged period of time [13-17]. This very little literature highlighted several negative consequences of restrictive measures, such as physical inactivity, unhealthy diet, mental stress, anxiety and the resulting increased cardiovascular risk burden. To our knowledge, this is the first analysis that assessed the impact of COVID-19 lockdown on a wide range of health parameters of heart failure patients who were forced to spend an extended time at home. Our analysis demonstrated a relative reduction of $21.6 \%$ of physical activity in the overall population over a 1 month period after the lockdown date. Eighty nine $\%$ of patients experienced this effect and $a \geq 25 \%$ relative reduction was observed for $43.3 \%$ of them. In agreement with our findings, Malanchini et al. [14] showed a decrease in physical activity of more than $25 \%$ for a range of $45.9-57.2 \%$ of patients during the lockdown period. This is of utmost concern for heart failure patients considering the benefits of physical activity in primary and secondary prevention of cardiovascular disease [18]. The reduction in physical activity affected both patients aged less than 70 years and those aged $\geq 70$ years. Moreover, our study showed that patients with marked physical activity reduction (i.e. $\geq 25 \%$ ) were more likely men. This result might be explained by the fact that women are generally more physically inactive than men [19]. We observed an inactivityinduced decrease of both mean HR and rHR in the entire population in the first month since lockdown was implemented. As expected, younger patients were shown to have higher variations of heart rate as compared with the overall population. On the contrary, physical inactivity during the lockdown period has not affected rHR in the elderly. On the other hand, a significant increase of mean HR was observed in patients over 70 years of age during COVID-19 lockdown. These findings in the elderly could be explained by two main factors: (1) habitual lower levels of physical activity and (2) the effect of psychological stress resulting from social 


\section{A Physical activity}

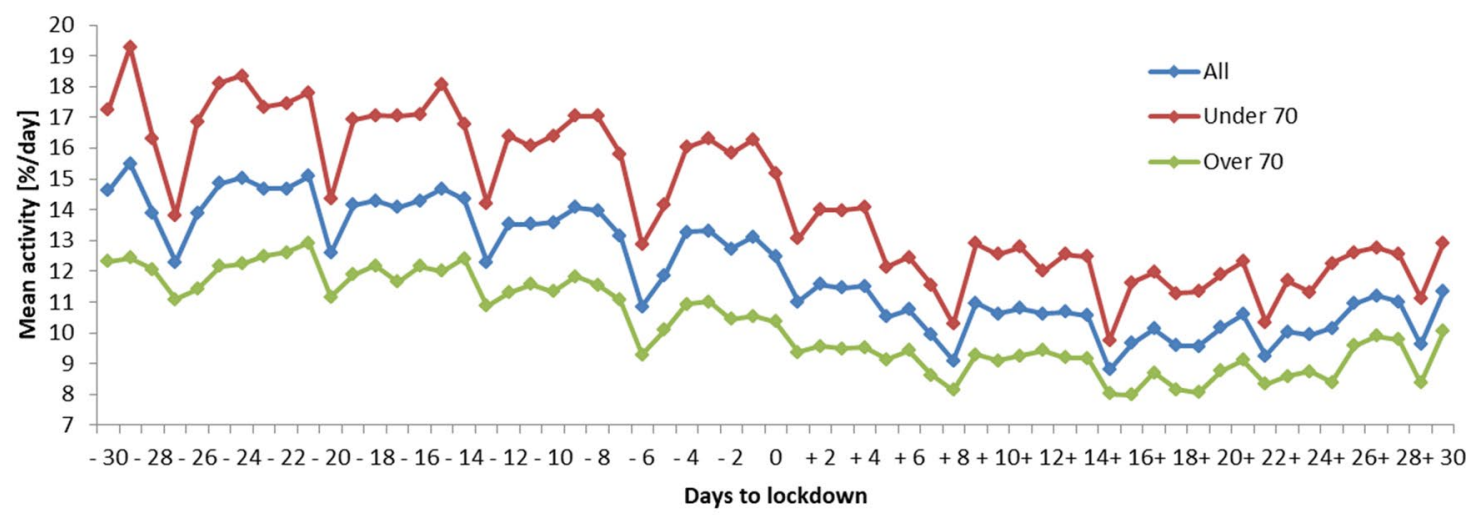

\section{B Thoracic Impedance}
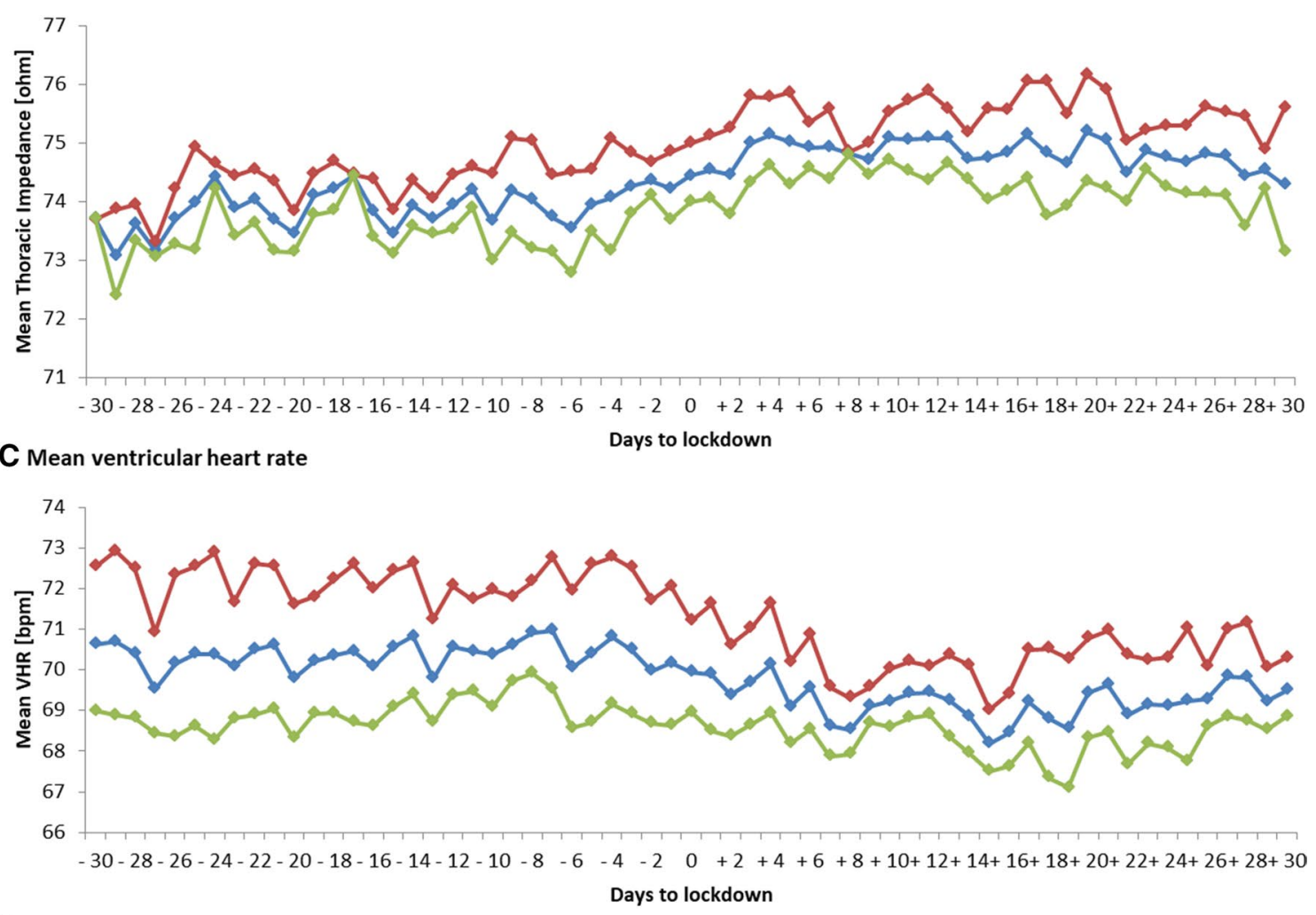

\section{Mean ventricular heart rate at rest}

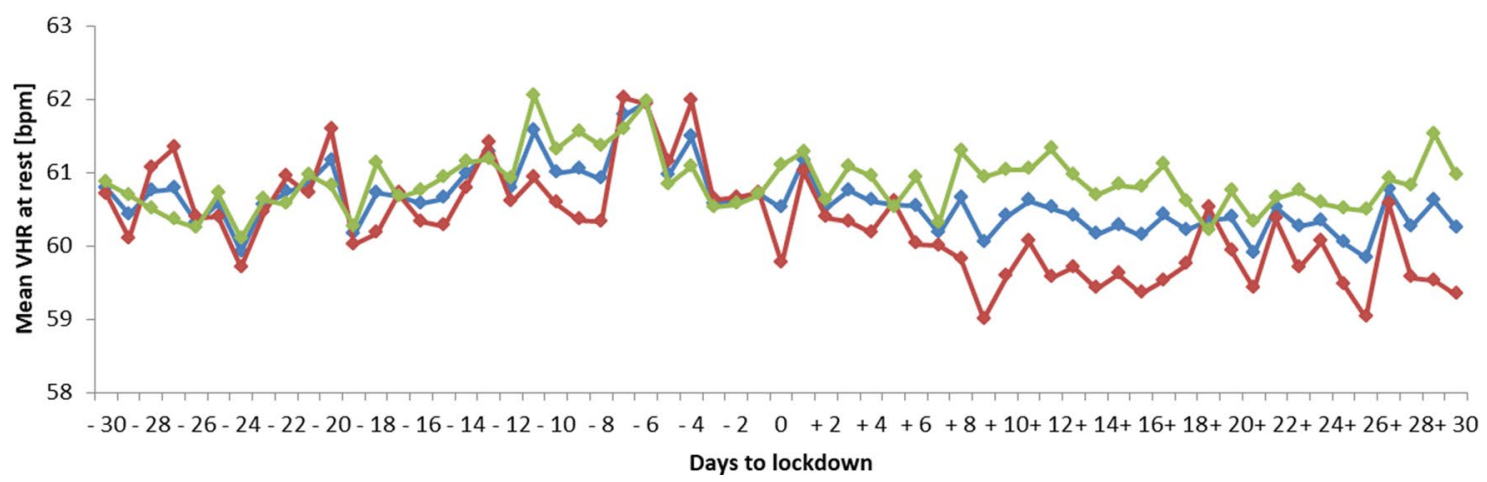

Fig. 1 Daily trends of remote monitoring variables during COVID-19 pandemic in the entire cohort $(n=180)$, in patients aged $<70$ years $(n=81)$ and $\geq 70$ years $(n=99)$. Time zero is the date of lockdown (8 March 2020) 
Fig. 2 Distribution of patients according to relative variation of median physical activity between the two consecutive 1 month time windows pre and post-lockdown

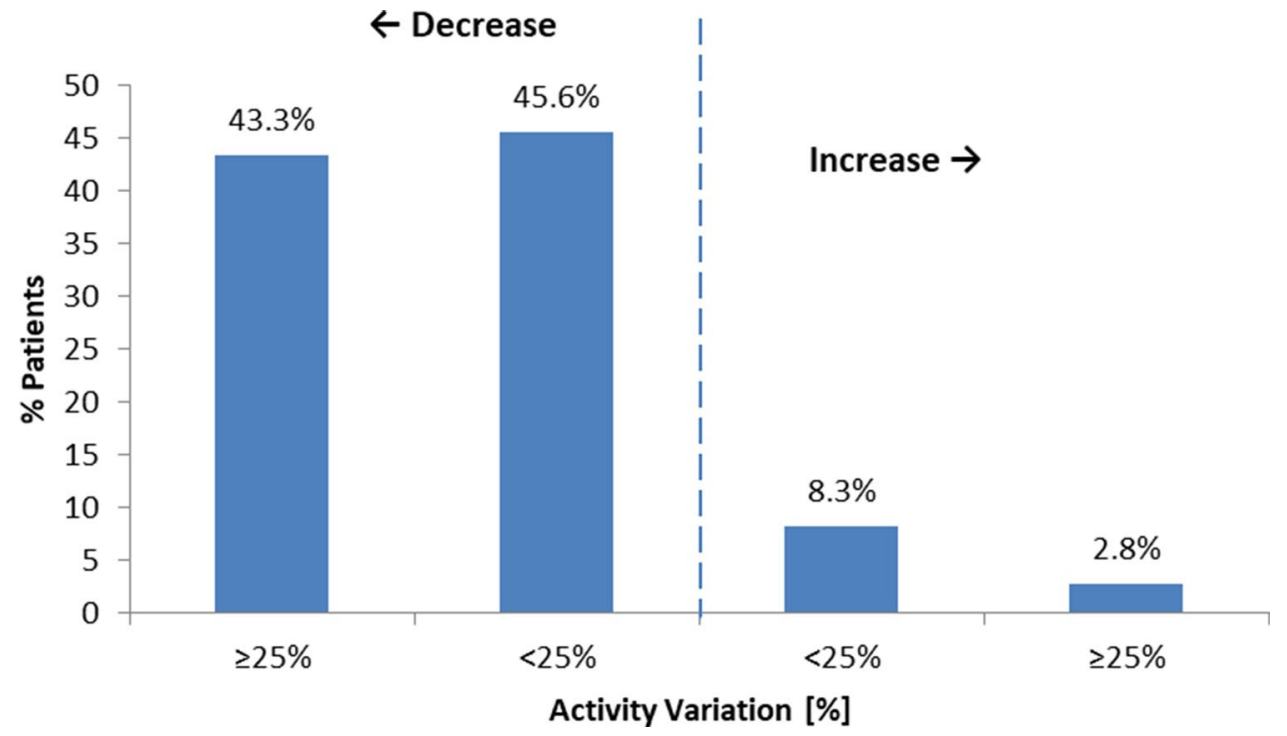

\begin{tabular}{llllr}
\hline & Total $(n=180)$ & $\begin{array}{l}\text { Patients with activity varia- } \\
\text { tion } \geq 25 \%(n=78)\end{array}$ & Others $(n=102)$ & $p$ value \\
\hline Sex (male) & $146(81.1)$ & $74(94.9)$ & $72(70.6)$ & $<0.001$ \\
Age (years) & $70(62-78)$ & $69.5(60-77)$ & $71(64-79)$ & 0.256 \\
\hline
\end{tabular}

Data are expressed as median (interquartile range), and $n(\%)$ for binary variable
Table 4 Characteristics of patients by level of physical activity variation lifestyle habits may differ from those of the general population. Finally, parameter variations were assessed only over limited observation periods to draw conclusions on longterm effects of COVID-19 lockdown. Nevertheless, there are scant data on the impact of lockdown on health parameters of cardiac patients, and therefore our analysis adds evidence on possible side effects of restrictive measures during a pandemic.

\section{Conclusion}

Our analysis explored the impact of COVID-19 lockdown on RM parameters in ICDs and CRT-Ds patients. In-home confinement quarantine caused a significant reduction not only of physical activity, but also of mean HR. In cardiac patients, the potential deleterious clinical effects of long-term lockdown may be carefully assessed and RM systems could be a valuable option for continuous health status surveillance.

Acknowledgements The authors would like to thank Lucia Annunziata, Sebastiano Lavorgna and Davide Zanini for technical support.

Author contribution All authors contributed to the study conception and design. Material preparation and data collection were performed by GM and EL. Data analysis was performed by PN and DG. The first draft of the manuscript was written by GM and all authors commented included subjects from a limited geographical area whose 
on previous versions of the manuscript. All authors read and approved the final manuscript.

Funding This research did not receive any specific grant from funding agencies in the public, commercial, or not-for-profit sectors.

\section{Declarations}

Conflicts of interest P.N. and D. G. are employees of BIOTRONIK Italia. All the remaining authors have no major conflicts of interest to disclose.

\section{References}

1. Rothan HA, Byrareddy SN (2020) The epidemiology and pathogenesis of coronavirus disease (COVID-19) outbreak. J Autoimmun 109:102433

2. Wang Y, Wang Y, Chen Y, Quin Q (2020) Unique epidemiological and clinical features of the emerging 2019 novel coronavirus pneumonia (COVID-19) implicate special control measures. J Med Virol 92:568-576

3. World Health Organization. Statement on the second meeting of the International Health Regulations (2005) Emergency Committee regarding the outbreak of novel coronavirus (2019-nCoV). https://www.who.int/news-room/detail/30-01-2020-statementon-the-second-meeting-of-theinternational-health-regulations(2005)-emergency-committee-regarding-theoutbreak-of-novelcoronavirus-(2019-ncov) (12 Mar 2020, date last accessed).

4. World Health Organization. Coronavirus Disease 2019 (COVID19) Situation report - 51. https://www.who.int/docs/defaultsource/coronaviruse/situation-reports/20200311-sitrep-51-covid19.pdf?sfvrsn=1ba62e57_10 (14 Jul 2020, date last accessed).

5. World Health Organization. (2020). Considerations in adjusting public health and social measures in the context of COVID-19: interim guidance, 16 April 2020. https://apps.who.int/iris/bitst ream/handle/10665/331773/WHO-2019-nCoV-Adjusting_PH_ measures-2020.1-eng.pdf? sequence $=1 \&$ is Allowed $=y(14 \mathrm{Jul}$ 2020, date last accessed).

6. World Health Organization. Coronavirus Disease 2019 (COVID19) Situation report - 46. https://www.who.int/docs/defaultsource/coronaviruse/situation-reports/20200306-sitrep-46-covid19.pdf?sfvrsn $1 / 496 b 04 a d f \_2$ (14 Jul 2020, date last accessed).

7. Istituto Superiore di Sanità. Epidemia COVID-19. Aggiornamento nazionale 4 agosto 2020 - appendice al bollettino con il dettaglio regionale. https://www.epicentro.iss.it/coronavirus/bollettino/ Bolletino-sorveglianza-integrata-COVID-19_4-agosto-2020_ appendix.pdf (10 Aug 2020, date last accessed).

8. Istituto Superiore di Sanità. Impatto dell'epidemia COVID-19 sulla mortalità totale della popolazione residente primo quadrimestre 2020. https://www.istat.it/it/files/2020/06/Rapp_Istat_ Iss_3Giugno.pdf (10 Aug 2020, date last accessed).

9. Fagiuoli S, Lorini FL, Remuzzi G (2020) Adaptations and lessons in the province of Bergamo. N Engl J Med 382:e71

10. Sebastiani G, Massa M, Riboli E (2020) Covid-19 epidemic in Italy: evolution, projections and impact of government measures. Eur J Epidemiol 35:341-345
11. Medeiros de Figueiredo A, Daponte Codina A, Moreira Marculino Figueiredo DC, Saez M, Cabrera León A (2020) Impact of lockdown on COVID-19 incidence and mortality in China: an interrupted time series study. Bull World Health Organ. https:// doi.org/10.2471/BLT.20.256701

12. Gregori D, Azzolina D, Lanera C, Prosepe I, Destro N, Lorenzoni G, Berchialla P (2020) A first estimation of the impact of public health actions against COVID-19 in Veneto (Italy). J Epidemiol Community Health 74(10):858-860

13. Mattioli AV, Nasi M, Cocchi C, Farinetti A (2020) COVID-19 outbreak: impact of the quarantine-induced stress on cardiovascular disease risk burden. Future Cardiol 16(6):539-542

14. Malanchini G, Malacrida M, Ferrari P, Leidi C, Ferrari G, Racheli M, Senni M, de Filippo P (2020) Impact of the coronavirus disease-19 outbreak on physical activity of patients with implantable cardioverter defibrillators. J Card Fail 26(10):898-899

15. Mattioli AV, Ballerini Puviani M, Nasi M, Farinetti A (2020) COVID-19 pandemic: the effects of quarantine on cardiovascular risk. Eur J Clin Nutr 74(6):852-855

16. Mattioli AV, Sciomer S, Cocchi C, Maffei S, Gallina S (2020) Quarantine during COVID-19 outbreak: changes in diet and physical activity increase the risk of cardiovascular disease. Nutr Metab Cardiovasc Dis 30(9):1409-1417

17. Brooks SK, Webster RK, Smith LE, Woodland L, Wessely S, Greenberg N, Rubin GJ (2020) The psychological impact of quarantine and how to reduce it: rapid review of the evidence. Lancet 395:912-920

18. Alves AJ, Viana JL, Cavalcante SL, Oliveira NL, Duarte JA, Mota J, Oliveira J, Ribeiro F (2016) Physical activity in primary and secondary prevention of cardiovascular disease: overview updated. World J Cardiol 8(10):575-583

19. Mattioli AV, Sciomer S, Moscucci F, Maiello M, Cugusi L, Gallina S, Dei Cas A, Lombardi C, Pengo M, Parati G, Barilla F, Ciccone MM, Palmiero P, Mercuro G, Maffei S (2019) Cardiovascular prevention in women: a narrative review from the Italian Society of Cardiology working groups on 'Cardiovascular Prevention, Hypertension and peripheral circulation' and on 'Women Disease. J Cardiovasc Med 20:575-583

20. Huang CJ, Webb HE, Zourdos MC, Acevedo EO (2013) Cardiovascular reactivity, stress, and physical activity. Front Physiol $4: 314$

21. Polak SB, Van Gool IC, Cohen D, Von der Thüsen JH, Van Paassen J (2020) A systematic review of pathological findings in COVID-19: a pathophysiological timeline and possible mechanisms of disease progression. Mod Pathol 33(11):2128-2138

22. Li M, Lei P, Zeng B, Li Z, Yu P, Fan B, Wang C, Li Z, Zhou J, Hu S, Liu H (2020) Coronavirus disease (COVID-19): spectrum of CT findings and temporal progression of the disease. Acad Radiol 27(5):603-608

23. De Simone V, Guardalben S, Guarise P, Padovani N, Giacopelli D, Zanotto G (2020) Home monitoring trends during COVID-19 infection. J Arrhythm 37(1):240-245

Publisher's Note Springer Nature remains neutral with regard to jurisdictional claims in published maps and institutional affiliations. 